\title{
New benzimidazole acridine derivative induces human colon cancer cell apoptosis in vitro via the ROS-JNK signaling pathway
}

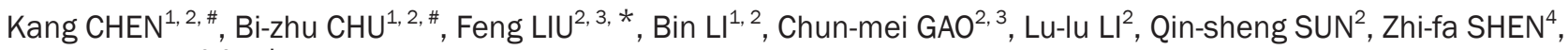 \\ Yu-yang JIANG ${ }^{2,3,5, *}$ \\ ${ }^{1}$ Department of Chemistry, Tsinghua University, Beijing 100084, China; ${ }^{2}$ The Ministry-Province Jointly Constructed Base for State Key \\ Lab-Shenzhen Key Laboratory of Chemical Biology, Graduate School at Shenzhen, Tsinghua University, Shenzhen 518055, China; \\ ${ }^{3}$ Shenzhen Anti-Tumor Drug Development Engineering Laboratory, Graduate School at Shenzhen, Tsinghua University, Shenzhen \\ 518055, China; ${ }^{4}$ Shenzhen Kivita Innovative Drug Discovery Institute, Shenzhen 518055, China; ${ }^{5}$ School of Medicine, Tsinghua \\ University, Beijing 100084, China
}

Aim: To investigate the mechanisms underlying anticancer action of the benzimidazole acridine derivative $\mathrm{N}-\{(1 \mathrm{H}-\mathrm{benzo}[\mathrm{d}] \mathrm{imidazol}-2-\mathrm{yl})$ methyl\}-2-butylacridin-9-amine (8m) against human colon cancer cells in vitro.

Methods: Human colon cancer cell lines SW480 and HCT116 were incubated in the presence of $8 \mathrm{~m}$, and then the cell proliferation and apoptosis were measured. The expression of apoptotic/signaling genes and proteins was detected using RT-PCR and Western blotting. ROS generation and mitochondrial membrane depolarization were visualized with fluorescence microscopy.

Results: $8 \mathrm{~m}$ dose-dependently suppressed the proliferation of SW480 and HCT116 cells with IC ${ }_{50}$ values of 6.77 and $3.33 \mu \mathrm{mol} / \mathrm{L}$, respectively. $8 \mathrm{~m}$ induced apoptosis of HCT116 cells, accompanied by down-regulation of Bcl-2, up-regulation of death receptor-5 (DR5), truncation of Bid, cleavage of PARP, and activation of caspases (including caspase- 8 and caspase- 9 as well as the downstream caspases-3 and caspase-7). Moreover, 8m selectively activated JNK and p38 without affecting ERK in HCT116 cells. Knockout of JNK1, but not p38, attenuated $\mathbf{8 m}$-induced apoptosis. In addition, $\mathbf{8 m}$ induced ROS production and mitochondrial membrane depolarization in HCT116 cells. Pretreatment with the antioxidants N-acetyl cysteine or glutathione attenuated $\mathbf{8 m}$-induced apoptosis and JNK activation in HCT116 cells.

Conclusion: The new benzimidazole acridine derivative, $8 \mathrm{~m}$ exerts anticancer activity against human colon cancer cells in vitro by inducing both intrinsic and extrinsic apoptosis pathways via the ROS-JNK1 pathway.

Keywords: benzimidazole acridine; anticancer drug; colon cancer; apoptosis; death receptor-5; JNK1; ROS

Acta Pharmacologica Sinica (2015) 36: 1074-1084; doi: 10.1038/aps.2015.44; published online 3 Aug 2015

\section{Introduction}

Colorectal carcinoma, one of the most common fatal cancers, is the second leading cause of cancer-related deaths worldwide ${ }^{[1]}$. The primary method currently used to treat all stages of colon cancer is surgery. After tumor excision, chemotherapeutic drugs, such as irinotecan (CPT-11), 5-fluorouracil (5-FU), and oxaliplatin, are typically used to further eradicate any residual tumor cells ${ }^{[2,3]}$. However, in the majority of cancer patients, currently available chemotherapies have had only partial suc-

\footnotetext{
\# These authors contributed equally to this work.

* To whom correspondence should be addressed.

E-mail jiangyy@sz.tsinghua.edu.cn (Yu-yang JIANG); liu.feng@sz.tsinghua.edu.cn (Feng LIU)

Received 2014-12-31 Accepted 2015-04-20
}

cess, owing to chemoresistance and side effects ${ }^{[4]}$. Therefore, there is an urgent need for highly efficacious alternative chemotherapeutic agents that can selectively induce apoptosis in cancer cells. Elaboration of the molecular mechanisms responsible for colon cancer progression should facilitate the development of effective chemotherapeutic agents.

Apoptosis, an intracellular suicide program possessing specific morphologic characteristics and biochemical features ${ }^{[5]}$, is a mechanism exploited by many anticancer drugs to effect cancer cell death. The extrinsic apoptotic pathway involves two important pro-apoptotic molecules that belong to the tumor necrosis factor (TNF) receptor superfamily, death receptor 4 (DR4) and death receptor 5 (DR5). DR4 and DR5 can be assembled into a death-inducing signaling complex (DISC) after binding to tumor necrosis factor (TNF)-related apoptosis- 
inducing ligand (TRAIL). Upon association with the adaptor molecule Fas-associated protein with death domain (FADD), DISC leads to the cleavage and activation of an apoptosis initiator, caspase-8, which activates the downstream caspases-3, -6 and -7 to culminate in the extrinsic apoptosis of malignant cells $^{[6,7]}$. Currently, a number of studies have suggested that many therapeutic agents, such as bioymifi, lapatinib, and etoposide, up-regulate DR5, thereby acting as key triggers of apoptosis in various cancer cell types in vitro and in vivo ${ }^{[8-10]}$. Crosstalk exists between the intrinsic and extrinsic apoptosis pathways: activated caspase- 8 in the extrinsic pathway cleaves Bid, after which the cleaved Bid translocates to mitochondria to cause the release of cytochrome $c$ and the subsequent initiation of the intrinsic apoptosis pathway ${ }^{[11]}$.

By triggering a variety of cellular responses leading to cell growth, differentiation, or cell death, reactive oxygen species (ROS) have recently been proposed to be involved in tumor metastasis as well as apoptosis induced by various compounds ${ }^{[12-14]}$. Cancer-induced ROS is controlled by antioxidants such as $\mathrm{N}$-acetyl cysteine (NAC) and glutathione (GSH) in cancer ${ }^{[15,16]}$. GSH is the most abundant thiol antioxidant in mammalian cells and maintains thiol redox in the cells. GSH depletion has been implicated in the etiology of various diseases, including cancer ${ }^{[17,18]}$. As a sulfhydryl donor, NAC not only contributes to the regeneration of GSH but also reacts directly with free ROS as its free thiol group is capable of interacting with electrophilic groups of $\operatorname{ROS}^{[19]}$. Two of the downstream molecules regulated by ROS are p-21 kinase $(\mathrm{PAK})$ and mitogen-activated protein kinase (MAPK) ${ }^{[20]}$. MAPKs include p38 MAPK, stress-activated protein kinase/ c-Jun NH2 terminal kinase (JNK), and extracellular signalregulated kinase (ERK). ERK is primarily involved in growth and survival, whereas JNK and p38 are generally associated with pro-apoptotic activities in many cell types ${ }^{[21]}$. JNK includes at least ten isoforms that are encoded by three genes, JNK1, JNK2, and JNK3. JNK1 and JNK2 are ubiquitously expressed, whereas expression of JNK3 is limited to the brain and heart ${ }^{[22]}$. Accumulating evidence suggests that JNK1 and JNK2 have different functions in the regulation of apoptosis and cell proliferation. Because of its importance in regulating apoptosis ${ }^{[23,24]}$, the JNK1 signal transduction pathway is of particular relevance to the work discussed here.

Substituted benzimidazole derivatives exhibit various bioactivities, such as anti-ulcerative ${ }^{[25]}$, anti-inflammatory ${ }^{[26]}$, antibacterial $^{[27]}$, and anti-carcinogenic properties ${ }^{[28]}$. Acridine and its derivatives are types of polycyclic aromatic compounds with п-conjugated structures that possess the ability to intercalate into DNA, subsequently inhibiting topoisomerases to elicit anticancer effects ${ }^{[29,30]}$. Many investigations have reported the relationship between benzimidazole or acridine derivatives and ROS- or JNK-mediated apoptosis ${ }^{[31-33]}$. However, apoptosis induced by a benzimidazole acridine derivative through the ROS-JNK1 pathway has never been studied. Our recent work has demonstrated that an analog of a benzimidazole acridine derivative $(8 \mathrm{~m})$ possess cytotoxic activity against a variety of cancer cell lines and can induce apoptosis of K562 human leukemia cells ${ }^{[34]}$. However, the effect of $8 \mathrm{~m}$ on human colon cancer cells and the mechanism by which it induces apoptosis is largely unknown. In this work, we investigated the molecular events responsible for $\mathbf{8 m}$-induced apoptosis in the HCT116 human colon cancer cell line. Our data provided sufficient evidence that $\mathrm{N}-\{(1 \mathrm{H}-$-benzo[d]imidazol-2-yl $)$ methyl\}-2-butylacridin-9-amine (8m)-induced apoptosis in HCT116 cells was strongly associated with activation of the ROS-JNK1 pathway.

\section{Materials and methods Materials}

8m was obtained from Associate Professor Chun-mei GAO of the Graduate School at Shenzhen, Tsinghua University (Shenzhen, China). Its molecular structure is shown in Figure 1A. Modified RPMI-1640 medium was purchased from HyClone (Logan, UT, USA). Fetal bovine serum (FBS) and Opti-MEM I reduced serum media were purchased from Gibco (Grand Island, NY, USA). Lipofectamine 2000, TRIzol Reagent and SlowFade ${ }^{\circledast}$ gold antifade mountant with DAPI were purchased from Invitrogen (Carlsbad, CA, USA). Annexin V-FITC (fluorescein isothiocyanate)/PI (propidium iodide) and 5,5',6,6'-tetrachloro-1,1',3,3'-tetraethyl-benzimidazol-carbocyanine iodide (JC-1) were purchased from eBioscience (San Diego, CA, USA). PrimeScript ${ }^{\mathrm{TM}}$ RT Master Mix (Perfect Real Time) kit and SYBR ${ }^{\circledast}$ Premix Ex Taq ${ }^{\mathrm{TM}}$ (Tli RNaseH Plus) kit were purchased from TaKaRa (Dalian, China). Short-interfering RNA (siRNA) was synthesized by GenePharma (Shanghai, China). Phosphor-SAPK/JNK (Thr183/Tyr185), SAPK/JNK, phosphor-p38, p38, phosphor-ERK, ERK, Bcl-2, Bid, cleaved caspase-9, cleaved caspase-8, cleaved caspase-7, cleaved caspase-3, and cleaved PARP were purchased from Cell Signaling Technology (Danvers, MA, USA). DR5 was obtained from Abcam (Cambridge, UK). $\beta$-Actin antibody, HRP-labeled Goat Anti-Rabbit IgG $(\mathrm{H} \pm \mathrm{L})$, HRP-labeled Goat Anti-Mouse IgG $(\mathrm{H} \pm \mathrm{L})$ and MTT (3-(4,5-dimethylthiazol-2-yl)-2,5-diphenyltetrazolium bromide) were purchased from Beyotime (Haimen, China). PVDF membrane, protease and phosphatase inhibitor cocktails were purchased from Roche (Mannheim, Germany). $\mathrm{N}$-acetylcysteine (NAC), L-glutathione reduced (GSH) and $2^{\prime}, 7^{\prime}$-Dichloro-dihydrofluorescein diacetate $\left(\mathrm{H}_{2}\right.$-DCFDA) were purchased from Sigma (St Louis, MO, USA).

\section{Cell culture}

All cells used in this study were obtained from the Cell Bank of the Chinese Academy of Sciences (Shanghai, China). HCT116 and SW480 were grown in RPMI-1640 supplemented with $10 \%$ FBS. All cells were cultured at $37^{\circ} \mathrm{C}$ in a humidified atmosphere containing $5 \% \mathrm{CO}_{2}$.

\section{Cell viability assay}

The MTT assay was used to examine the growth inhibitory effect of $8 \mathrm{~m}$. Cells were plated in 96-well culture plates at a cell density of 5000 cells per well in $100 \mu \mathrm{L}$ of complete medium and incubated under standard cell culture conditions for $12 \mathrm{~h}$. The medium was then removed and replaced 
with fresh medium containing the vehicle control or different concentrations of $8 \mathrm{~m}(1,2.5,5,10,25$, and $50 \mu \mathrm{mol} / \mathrm{L})$ for $48 \mathrm{~h}$. After agent treatment, the cells were incubated for $4 \mathrm{~h}$ in a medium containing $15 \mu \mathrm{L}$ of MTT $(5 \mathrm{mg} / \mathrm{mL})$ solution. The formazan precipitate was dissolved in $100 \mu \mathrm{L}$ of DMSO, and the absorbance at $490 \mathrm{~nm}$ was measured by a Multimode Detector DTX880 (Beckman Coulter, Atlanta, GA, USA).

\section{Colony formation assay}

HCT116 cells were seeded into 6 -well plates $\left(1 \times 10^{3}\right.$ cells/ well) and cultured overnight. Then, the culture medium was replaced with fresh medium containing the vehicle control or the indicated concentrations of $\mathbf{8 m}$ (or co-cultured with 5 $\mathrm{mmol} / \mathrm{L} \mathrm{NAC}$ ) for $14 \mathrm{~d}$. The culture medium was changed every 3 to $4 \mathrm{~d}$. When colonies formed, the medium was then discarded, and each well was washed twice with PBS. After that, colonies were fixed with $100 \%$ cold ethanol for $30 \mathrm{~min}$ and then stained with $0.05 \%$ crystal violet.

\section{Apoptotic nuclear measurement}

Cells were seeded onto cover slides for $12 \mathrm{~h}$ and then treated with the vehicle control or various concentrations $(5,7.5$, and $10 \mu \mathrm{mol} / \mathrm{L}$ ) of $8 \mathrm{~m}$ for $24 \mathrm{~h}$. After the cells were washed with cold PBS, the cells were fixed in $4 \%$ paraformaldehyde for $10 \mathrm{~min}$. The cells were subsequently washed with PBS and stained with 4,6-diamidino-2-phenylindole (DAPI) for $30 \mathrm{~min}$ in the dark at room temperature. Cover slips containing the cells were then washed with PBS-TX (10 mL PBS+10 $\mu \mathrm{L} 10 \%$ Tritonx-100) three times, and images were taken using a fluorescent microscope (Olympus, Tokyo, Japan).

\section{ROS generation assay}

Oxidative stimuli present in the cytoplasm may be transmitted to the nucleus through cellular signal transduction pathways to regulate cell division and survival. 2', $7^{\prime}$-Dichloro-dihydrofluorescein diacetate $\left(\mathrm{H}_{2}\right.$-DCFDA, Molecular Probes) is metabolized by nonspecific esterases to the non-fluorescent product, $2^{\prime}, 7^{\prime}$-dichloro-dihydrofluoresceine, which is then oxidized by ROS to the fluorescent product DCF. HCT116 cells were incubated in $60 \mathrm{~mm}$ culture dishes under standard cell culture conditions for $12 \mathrm{~h}$ and then treated with $0,5,7.5$, or $10 \mu \mathrm{mol} / \mathrm{L}$ $8 \mathrm{~m}$ for $24 \mathrm{~h}$. After incubation and washing with PBS, the cells were loaded with $10 \mu \mathrm{mol} / \mathrm{L} \mathrm{H}_{2}$-DCFDA in complete medium for $1 \mathrm{~h}$ at $37^{\circ} \mathrm{C}$. After the removal of excessive $\mathrm{H}_{2}$-DCFDA, the cells were analyzed by a fluorescent microscope at an excitation wavelength of $485 \mathrm{~nm}$ and an emission wavelength of 530 nm.

\section{Visualization of mitochondrial membrane potential}

Mitochondrial membrane potential (MMP) was assessed using 5,5',6,6'-tetrachloro-1,1',3,3' -tetraethyl-benzimidazolcarbocyanine iodide (JC-1). HCT116 cells were incubated in $60-\mathrm{mm}$ culture dishes under standard cell culture conditions for $12 \mathrm{~h}$ and then treated with $0,5,7.5$, or $10 \mu \mathrm{mol} / \mathrm{L} 8 \mathrm{~m}$ for $24 \mathrm{~h}$. After treatment with $8 \mathrm{~m}$, the cells were incubated for 30 min at $37^{\circ} \mathrm{C}$ with $1 \mu \mathrm{g} / \mathrm{mL}$ of JC- 1 in growth medium. MMP depolarization was visualized under a fluorescent microscope by measuring fluorescence at an excitation wavelength of 485 $\mathrm{nm}$ and emission wavelengths of $530 \mathrm{~nm}$ and $590 \mathrm{~nm}$.

\section{Flow cytometric quantification of apoptosis}

Apoptosis was determined by Annexin V-FITC and PI double staining. HCT116 cells were cultured in $60-\mathrm{mm}$ dishes in a humidified $5 \% \mathrm{CO}_{2}$ atmosphere at $37^{\circ} \mathrm{C}$ overnight and then were treated with the vehicle control or various concentrations ( 5 or $7.5 \mu \mathrm{mol} / \mathrm{L}$ ) of $8 \mathrm{~m}$ for $24 \mathrm{~h}$. After trypsinization at the indicated time points, the cells were centrifuged at $400 \times g$ for $10 \mathrm{~min}$ at $4{ }^{\circ} \mathrm{C}$, washed twice with cold PBS at the same centrifugation speed, and re-suspended in $400 \mu \mathrm{L}$ of Annexin V-FITC binding buffer. The cells were then incubated with $5 \mu \mathrm{L}$ of Annexin V-FITC and $5 \mu \mathrm{L}$ of Propidium Iodide (PI) for $15 \mathrm{~min}$ at room temperature protected from light, as per the manufacturer's instructions. The harvested cells, both adherent and floating cells, were analyzed by fluorescence activated cell sorting (FACS) using a flow cytometer (Beckman Coulter, Atlanta, GA, USA).

\section{Transfection with siRNA}

For RNA interference, cells were seeded at a density of $2 \times 10^{5}$ / well in $60-\mathrm{mm}$ dishes. Lipofectamine 2000 transfection reagent was used to silence JNK1, JNK2, and p38. A nonspecific siRNA was used as a control. A final concentration of 75 $\mathrm{nmol} / \mathrm{L}$ siRNA was transfected into cells by standard protocols according to the manufacturer's instructions. Twentyfour hours after transfection, the cells were washed with PBS, the culture medium was replaced, and the cells were stimulated with the vehicle control or $5 \mu \mathrm{mol} / \mathrm{L} 8 \mathrm{~m}$. The siRNA sequences of the target genes are as follows: JNK1 (sense: 5'-GGCAUGGGCUACAAAGAAAtt-3' and antisense: 5'UUUCUUUGUAGCCCAUGCCtt-3'); JNK2 (sense: $5^{\prime}$-GACUCAACCUUCACUGUCCUAtt-3' and antisense: 5'-UAGGACAGUGAAGGUUGAGUCtt-3'); p38 (sense: 5'-GAACUGCGGUUACUUAAACtt-3' and antisense: 5'-GUUUAAGUAACCGCAGUUCtt-3'); and nonspecific (sense: 5'-UUCUCCGAACGUGUCACGUtt-3' and antisense: 5' ${ }^{\prime}$-ACGUGACACGUUCGGAGAAtt-3'). The efficiency of JNK and p38 protein silencing was analyzed by Western blot at 24 and $48 \mathrm{~h}$.

\section{RNA isolation and real-time PCR analysis}

Total RNA from tumor cells was isolated using the TRIzol reagent according to the manufacturer's instructions. The purity of RNA samples was determined by their $\mathrm{OD}_{260 / 280}$ $(>1.8)$. First-strand cDNA was synthesized with $500 \mathrm{ng}$ of total RNA using a PrimeScript ${ }^{\mathrm{TM}}$ RT Master Mix (Perfect Real Time) kit. Gene expression was quantified using a SYBR $^{\oplus}$ Premix Ex Taq $^{\text {TM }}$ (Tli RNaseH Plus) kit on an ABI 7500 (Applied Biosystems, Carlsbad, CA, USA). The expression level of each mRNA was normalized with respect to that of glyceraldehyde-3-phosphate dehydrogenase (GAPDH). The primers used for PCR were DR4 (sense: 5'-GCAGCTGGACCTCACGAAAA- ${ }^{\prime}$ and antisense: $5^{\prime}$-CCTGGGCCTGCTGTACCA-3'); DR5 (sense: 5'-GGCCACAGGGACACCTT- 
GTA-3' and antisense: 5'-TCGCCCGGTTTTGTTGA-3'); c-Fos (sense: 5'-GAGGGGCAAGGTGGAACAGT-3' and antisense: 5'-CTTGCAGGCAGGTCGGTGAG-3'); and GAPDH (sense: 5'-TGGCAAATTCCATGGCACCG-3' and antisense: 5'-CGCCCCACTTGATTTTGGAGG-3').

\section{Western blot}

After treatment, the cells were washed twice with ice-cold PBS, and the reaction was terminated by the addition of icecold lysis buffer (10 mmol/L HEPES (pH 7.9), $10 \mathrm{mmol} / \mathrm{L}$ $\mathrm{KCl}, 1 \mathrm{mmol} / \mathrm{L}$ EDTA, 0.1\% NP-40) including freshly added protease and phosphatase inhibitor cocktails. Lysates were cleared by centrifugation at $20000 \times g, 4{ }^{\circ} \mathrm{C}$ for $10 \mathrm{~min}$, and the supernatant was snap frozen at $-80^{\circ} \mathrm{C}$. Thirty micrograms of total protein was separated in 12\% SDS-polyacrylamide gels and electrophoretically transferred onto PVDF membranes. After blocking with 5\% (w/v) BSA in TBST buffer $(10 \mathrm{mmol} / \mathrm{L}$ Tris- $\mathrm{HCl}, 150 \mathrm{mmol} / \mathrm{L} \mathrm{NaCl}$, and $0.05 \%$ v/v Tween-20, $\mathrm{pH} 7.8$ ) for $2 \mathrm{~h}$ at room temperature, the membranes were incubated with the specific primary antibody $(1: 1000)$ overnight at $4{ }^{\circ} \mathrm{C}$. Following incubation with an HRP-conjugated secondary antibody (1:3000) and after incubating the membrane in SuperSignal West Pico Chemiluminescent Substrate (Pierce, Rockford, IL, USA), protein bands were visualized on an imaging system (Bio-Rad, Munich, Germany).

\section{Statistical analysis}

All values are presented as the mean \pm SEM from experiments performed in triplicates. Significance was determined using Student's $t$-test; $P<0.05$ was considered statistically significant.

\section{Results}

Cytotoxicity and apoptosis induced by $8 \mathrm{~m}$ against human colon cancer cells

The potential of $\mathbf{8 m}$ (Figure 1A) to induce cell death in human colon cancer cells was examined using the MTT assay. Treatment of SW480 and HCT116 cells with 8m induced cell death in a concentration-dependent manner, and the $50 \%$ inhibitory concentrations $\left(\mathrm{IC}_{50}\right)$ of $\mathbf{8 m}$ against SW480 and HCT116 cells were $6.77 \pm 0.19 \mu \mathrm{mol} / \mathrm{L}$ and $3.33 \pm 0.02 \mu \mathrm{mol} / \mathrm{L}$, respectively (Figure 1B, 1C). To confirm that the enhanced cytotoxic effects by $8 \mathrm{~m}$ in HCT116 cells were due to increased apoptosis, we examined the apoptotic response using FITC-annexin V/PI double staining flow cytometric analysis. After $24 \mathrm{~h}$ of treatment, we found that 5 and $7.5 \mu \mathrm{mol} / \mathrm{L} 8 \mathrm{~m}$ induced apoptosis in $21.09 \%$ and $27.95 \%$ of HCT116 cells, respectively(Figure 1D). Using DAPI staining, we then examined cells for morphological features of apoptosis, such as condensed chromatin and apoptotic bodies (Figure 1E). Collectively, these results suggested that $\mathbf{8 m}$ exhibited potential antitumor activity, at least in part, by inducing apoptosis in colon cancer cells.

$8 \mathrm{~m}$-induced apoptosis involves both the extrinsic and intrinsic apoptotic pathways

To ascertain the underlying mechanisms responsible for enhancement of apoptotic cell death, we examined the effects of $\mathbf{8 m}$ on the expression of apoptosis-related genes and proteins. To determine whether $\mathbf{8} \mathbf{m}$ acts through the extrinsic apoptotic pathway, the expression levels of two members of the tumor necrosis factor (TNF) receptor superfamily, DR4 and DR5, which are upstream mediators of the extrinsic apoptosis pathway ${ }^{[6]}$, were examined after $8 \mathrm{~m}$ treatment. Real-time PCR analysis revealed increased DR4 and DR5 mRNA levels, with DR5 increasing more significantly than DR4, suggesting that DR5 may play a more important role than DR4 in mediating $8 \mathrm{~m}$-induced apoptosis $(P<0.05$, Figure $2 \mathrm{~A})$. We then examined the expression of DR5 at the protein level and found that DR5 protein expression was induced by $\mathbf{8 m}$ in a concentration- and time-dependent manner. The cleavage and truncation of Bid and caspase- 8 , two downstream effectors, were induced by $8 \mathrm{~m}$, as indicated by western blotting (Figure 2B, 2C). These results suggested that $\mathbf{8 m}$ induced apoptosis through the extrinsic apoptotic pathway.

Bcl-2 tightly regulates the release of cytochrome $c$ from the mitochondria, thus controlling the initiation of intrinsic apoptotic pathways ${ }^{[35]}$. Following $8 \mathrm{~m}$ treatment, Bcl-2 and caspase-9, two hallmarks of the intrinsic apoptotic pathway, were down-regulated and cleaved, respectively, in a concentration- and time-dependent manner (Figure 2B, 2C). These results suggested that $8 \mathrm{~m}$ also induced apoptosis through the intrinsic apoptosis pathway. Furthermore, the subsequent activation of caspase-7, caspase- 3 and poly (ADP-ribose) polymerase (PARP) were observed (Figure 2B, 2C). Collectively, these data suggested that $8 \mathrm{~m}$-induced apoptosis involved both the extrinsic and the intrinsic apoptotic pathways.

\section{$8 \mathrm{~m}$ activated mitogen-activated protein kinase signaling}

MAPK signaling can be activated in response to a variety of extracellular stimuli, including mitogens, heat shock and osmotic stress, and can regulate the levels of DRs, Bcl-2, and other apoptosis-related proteins ${ }^{[36-38]}$. To determine whether MAPK is involved in apoptosis after $\mathbf{8 m}$ treatment, we examined the effects of $\mathbf{8 m}$ on the activation of MAPK pathways. Treatment of HCT116 cells with $8 \mathrm{~m}$ increased the amounts of phosphorylated JNK and p38, which reflect the activated states of these two kinases, in a dose-dependent manner. However, the phosphorylation of ERK was minimally affected (Figure $3 \mathrm{~A})$. Our subsequent analysis of the time course of JNK and p38 activation showed that the phosphorylation of JNK and p38 were time-dependent: both were induced at $4 \mathrm{~h}$ after exposure to $8 \mathrm{~m}$, reaching a maximum level at $12 \mathrm{~h}$, with activity persisting until $24 \mathrm{~h}$. Fluctuations in levels of phosphorylated ERK were barely apparent during this time period (Figure 3B). In addition, we noted that c-Fos, a well-known JNK substrate, was also up-regulated by $\mathbf{8 m}$ treatment in the HCT116 colon cancer cell line $(P<0.05$, Figure $2 \mathrm{~A})$.

\section{JNK1 played an important role in $8 m$-induced apoptosis}

To further investigate the role of MAPK activation in $\mathbf{8 m}$-induced apoptosis, we treated HCT116 cells with 8m 
A

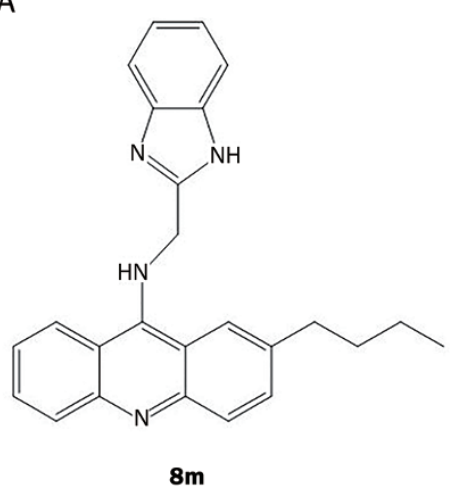

B

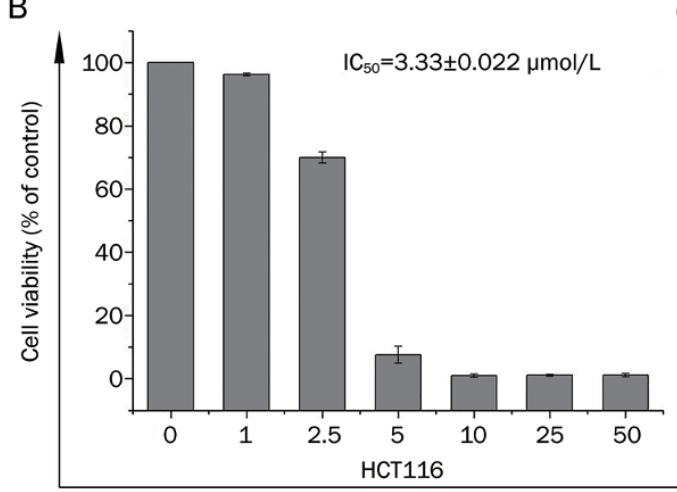

C

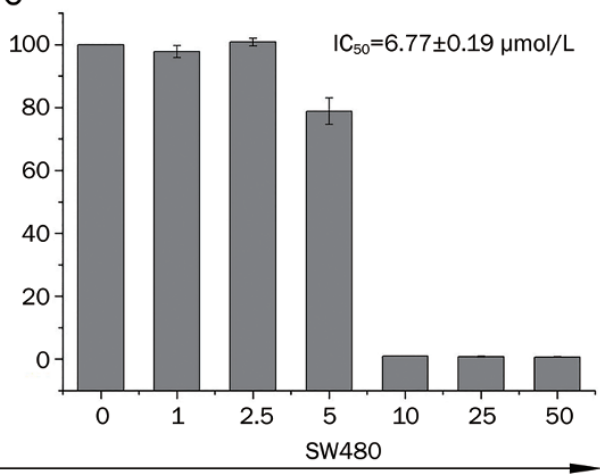

Concentration ( $\mu \mathrm{mol} / \mathrm{L})$

D

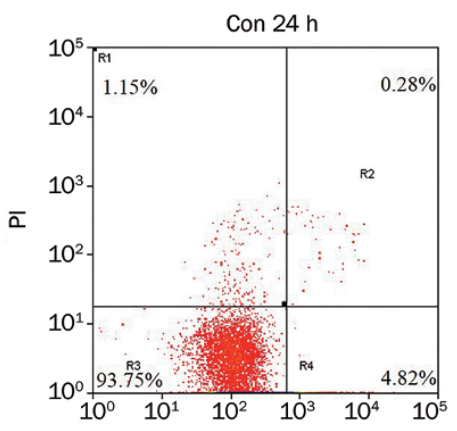

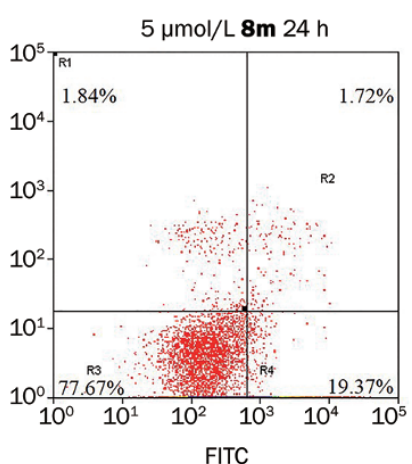

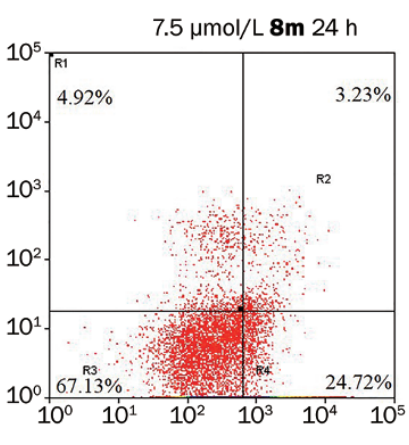

E

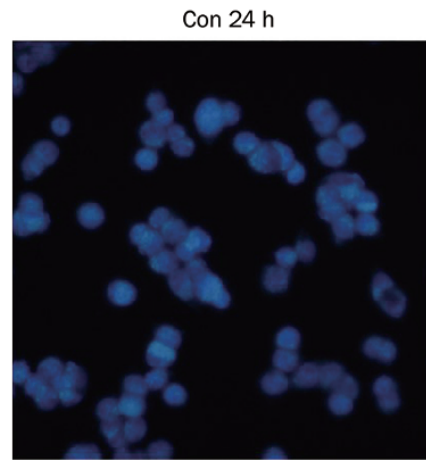

$5 \mu \mathrm{mol} / \mathrm{L} \mathbf{8 m} 24 \mathrm{~h}$

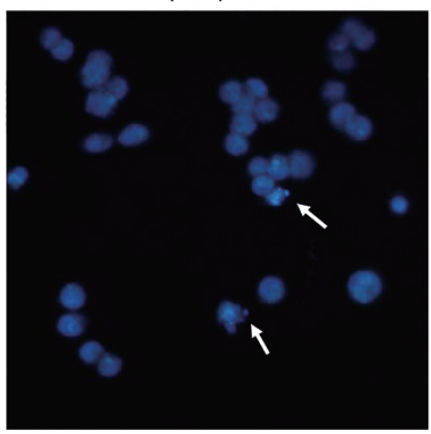

$7.5 \mu \mathrm{mol} / \mathrm{L} 8 \mathrm{~m} 24 \mathrm{~h}$

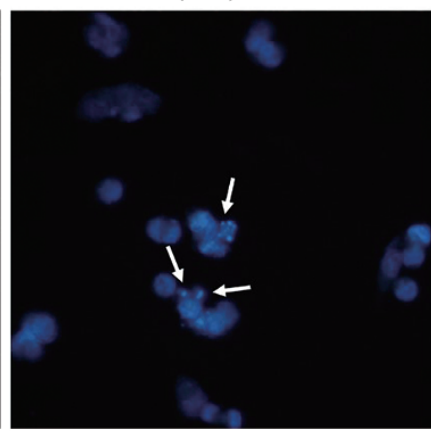

$10 \mu \mathrm{mol} / \mathrm{L} \mathbf{8 m} 24 \mathrm{~h}$

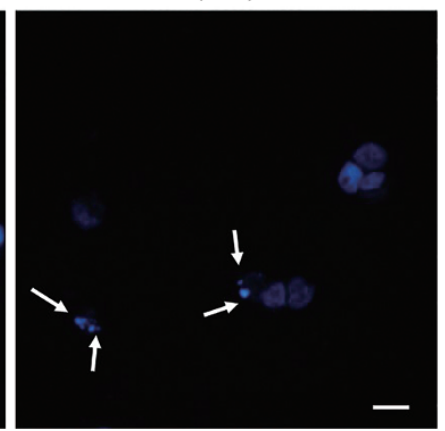

Figure 1. The effects of $\mathbf{8 m}$ on the viability of human colon cancer cells. (A) Chemical structure of $\mathbf{8 m}(\mathrm{N}-((1 \mathrm{H}-$ benzo[d]imidazol-2-yl)methyl)-2butylacridin-9-amine, $\mathrm{C}_{25} \mathrm{~N}_{4} \mathrm{H}_{24}$ ). HCT116 cells (B) or SW480 cells (C) were incubated with the indicated concentrations of $8 \mathrm{~m}$ for $48 \mathrm{~h}$ in $96-$-well plates, and cell viability was examined by the MTT assay. (D) HCT116 cells were treated with the indicated concentrations of $8 \mathbf{m}$ for $24 \mathrm{~h}$, and apoptosis was detected by flow cytometry. (E) HCT116 cells were stained with DAPI and assessed by fluorescence microscopy. Apoptotic cells exhibited apoptotic bodies and chromatin condensation. Scale bar, $20 \mu \mathrm{m}$.

after inhibiting the expression of JNK1, JNK2, and p38 via the addition of the indicated oligonucleotides. The effects of JNK1, JNK2, and p38 siRNA were still observable 48 h posttreatment, outlasting the duration of $8 \mathrm{~m}$ treatment in the subsequent detection assays (Figure 4A, 4C). Compared with control siRNA, Western blotting analyses showed that JNK1 siRNA completely abolished not only the $8 \mathrm{~m}$-induced increase in phosphorylated-JNK (phosphor-JNK) but also partially blocked the $8 \mathrm{~m}$-induced up-regulation of DR5, down-regulation of Bcl-2 as well as cleavage of Bid, caspase-8, caspase-7, caspase-3, and PARP. However, other than the decrease in the intensity of the Bcl-2 band, transfection with JNK2 siRNA appeared to elicit opposite results (Figure 4B). We then examined the effects of p38 siRNA, which, unexpectedly, reduced the level of phosphorylated p38; however, p38 siRNA did not affect the levels of other apoptosis-related proteins (Figure 4D). These results suggested that JNK1 played an important role in mediating both the extrinsic and intrinsic apoptotic pathways induced by $8 \mathrm{~m}$. This result was further supported by our flow cytometry data, which demonstrated that JNK1 siRNA, compared with the control siRNA, rescued $8 \mathrm{~m}$-induced apoptosis (Figure 4E). 
A

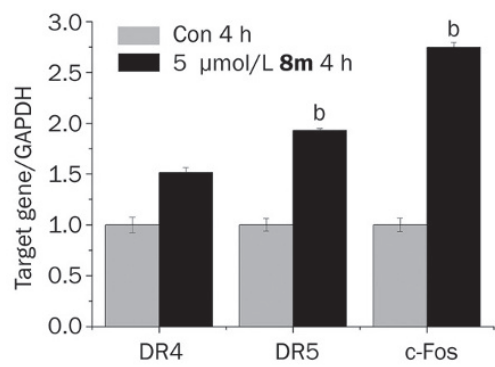

B

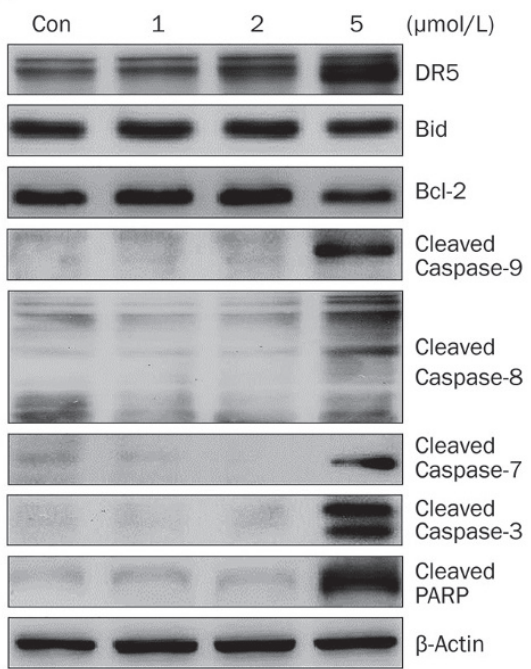

C

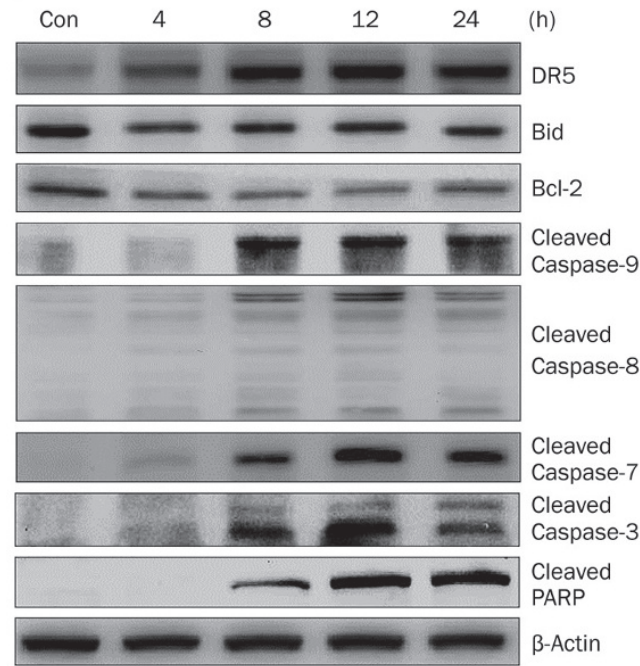

Figure 2. $\mathbf{8 m}$ induction of apoptotic gene and protein expression. (A) HCT116 cells were treated with $\mathbf{8 m}$ at $5 \mu \mathrm{mol} / \mathrm{L}$ for $4 \mathrm{~h}$ before real-time PCR was performed. Gene expression of three indicated genes as shown relative to control cells $\left({ }^{b} P<0.05\right.$ vs control). (B) HCT116 cells were treated with the specified concentration of $\mathbf{8 m}$ for $24 \mathrm{~h}$, and whole cell extracts were analyzed by Western blot using the indicated antibodies. $\beta$-Actin protein was used as an internal control. (C) HCT116 cells were treated with $5 \mu \mathrm{mol} / \mathrm{L} \mathbf{8 m}$ for $4,8,12$, or $24 \mathrm{~h}$. Whole cell extracts were analyzed by Western blot using the indicated antibodies.
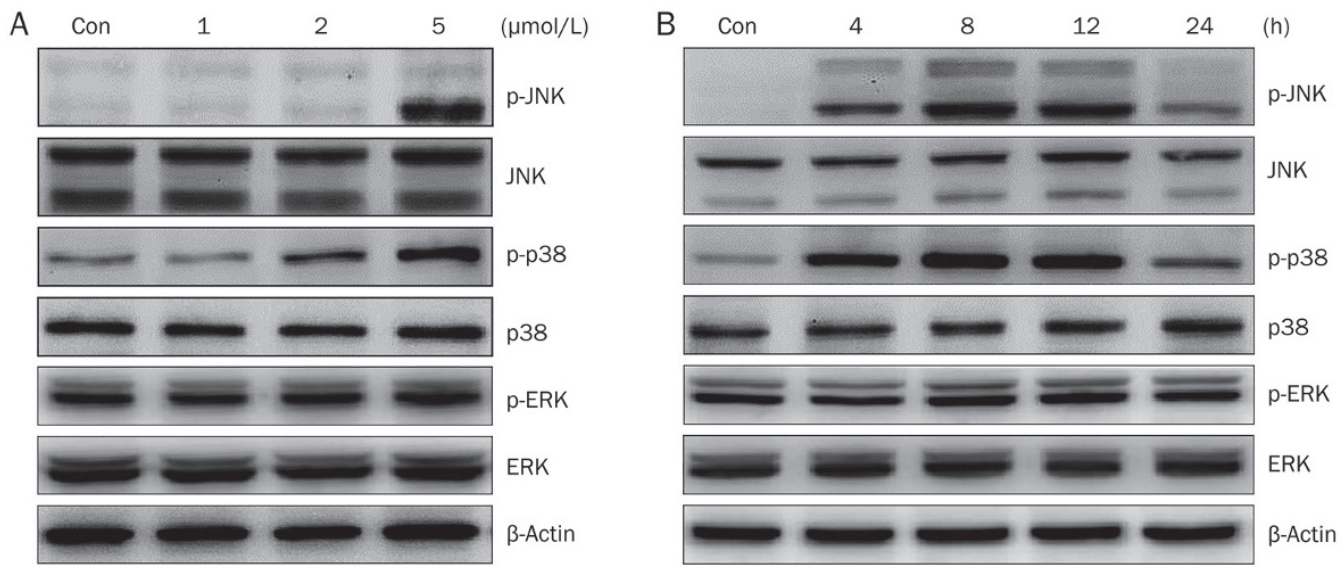

Figure 3. Effects of $\mathbf{8 m}$ on MAPK activation. Phosphorylation of JNK, p38 MAP kinase, and ERK in cell lysates was detected by immunoblot analysis using the indicated antibodies. (A) HCT116 cells were treated with the indicated concentrations of $\mathbf{8 m}$ for $24 \mathrm{~h}$. (B) HCT116 cells were treated with 5 $\mu \mathrm{mol} / \mathrm{L} \mathbf{8 m}$ for $4,8,12$, or $24 \mathrm{~h}$.

\section{8m-induced apoptosis was ROS-dependent}

Because oxidative stress and mitochondrial membrane depolarization can each induce cancer cell apoptosis, we examined these two indicators after $8 \mathrm{~m}$ treatment. Using a fluorescent microscope, we determined the intracellular ROS level by measuring the oxidation of non-fluorescent $\mathrm{H}_{2}$-DCFDA to its highly fluorescent derivative $2^{\prime}, 7^{\prime}$-dichlorofluorescein (DCF). As shown in Figure 5A, 8m stimulated ROS formation in a concentration-dependent manner. JC- 1 is a membrane-permeable dye whose maximal fluorescence emission changes from $\sim 590 \mathrm{~nm}$ to $\sim 530 \mathrm{~nm}$ when the mitochondrial membrane depo- larizes. By measuring the shift in the fluorescence emission peak using fluorescence microscopy, we found that $8 \mathrm{~m}$ treatment induced mitochondrial depolarization in a concentrationdependent manner (Figure 5B). Because both the DR and the mitochondrial apoptotic pathways mediated by JNK could be ROS-dependent ${ }^{[13,39]}$, two antioxidative ROS scavengers, GSH and NAC, were used to ascertain the relationship between $8 \mathrm{~m}$-induced cell death and ROS. Both scavengers reduced phosphor-JNK and the levels of other $\mathbf{8 m}$-induced apoptotic proteins as well as the degree of cleavage of specific apoptotic mediators. The cleavage of caspase-7 and PARP were com- 
A

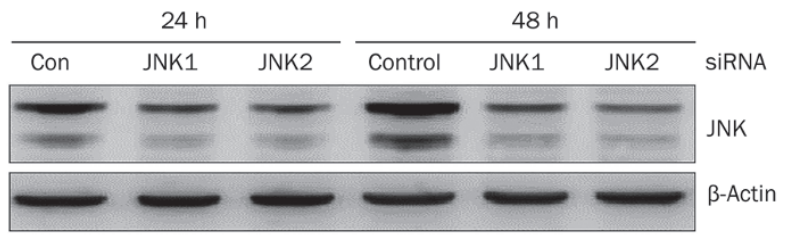

C

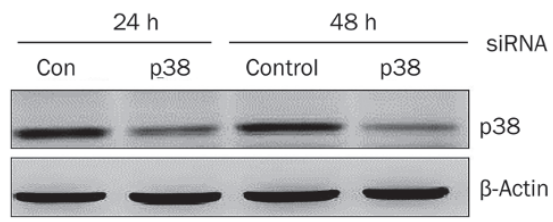

D

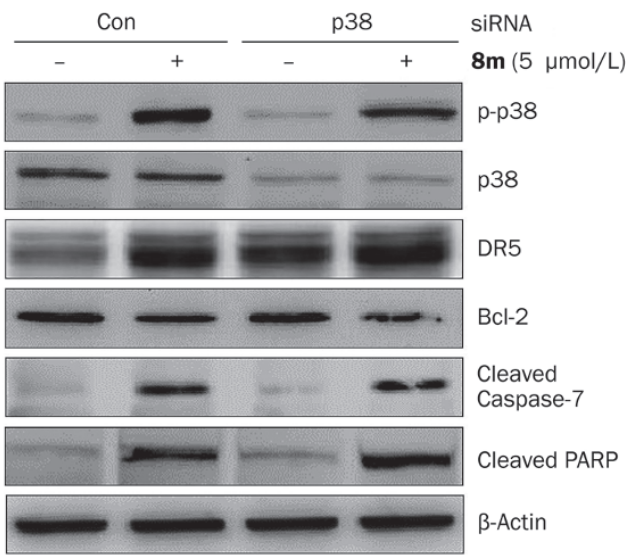

E

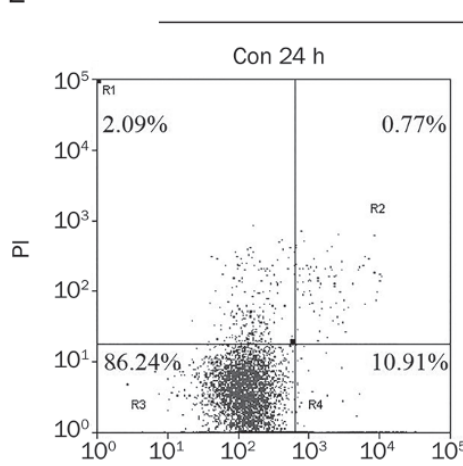

Con

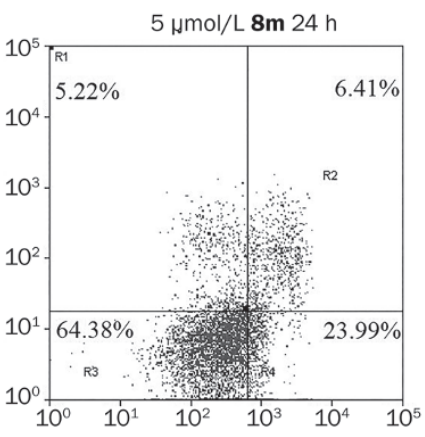

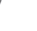

B
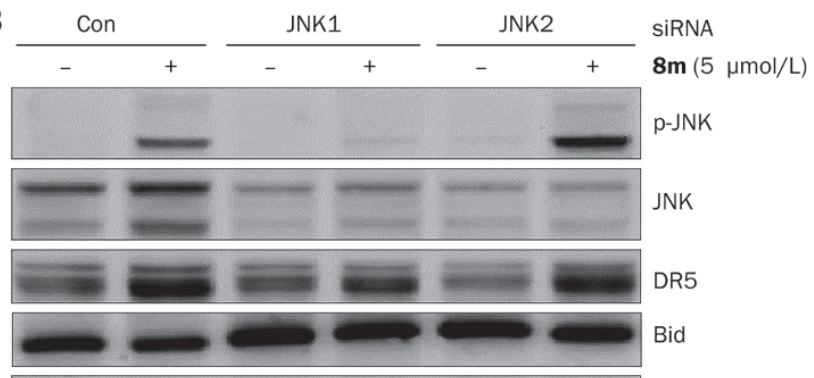

$-20 \mathrm{BCl}-2$
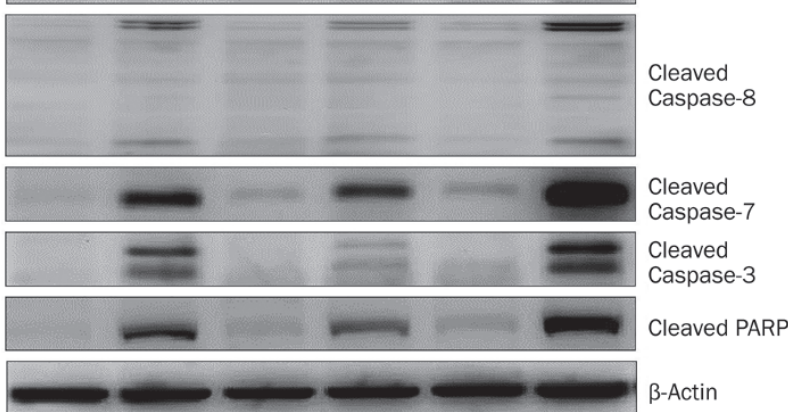

-JNK

NK

. 2

Cleaved aspase-8 
A
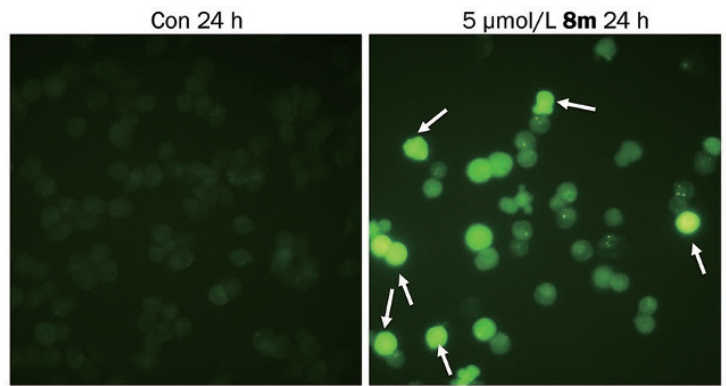

B
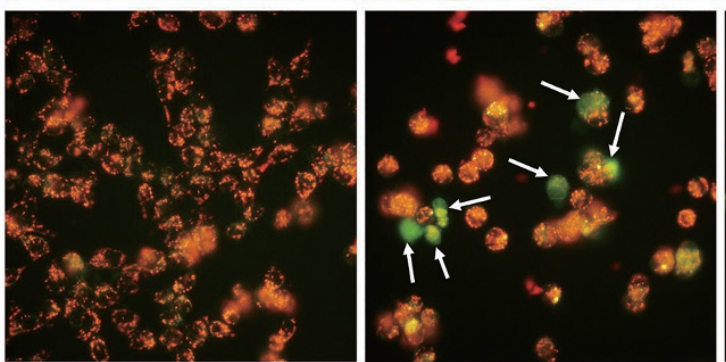

C $\quad$ GSH

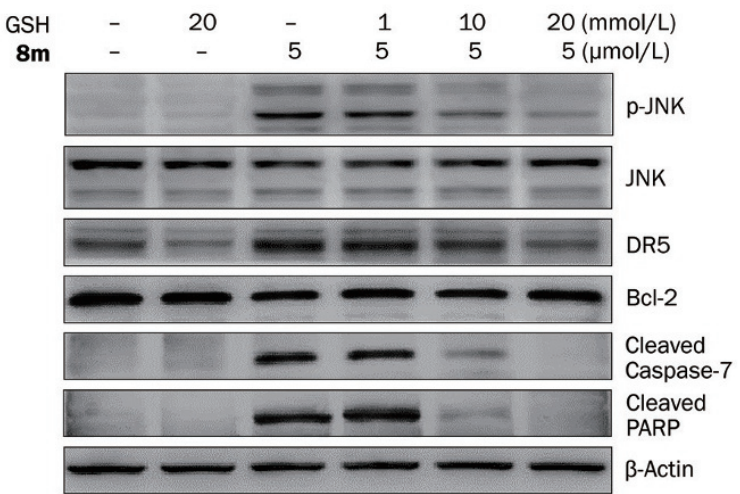

E

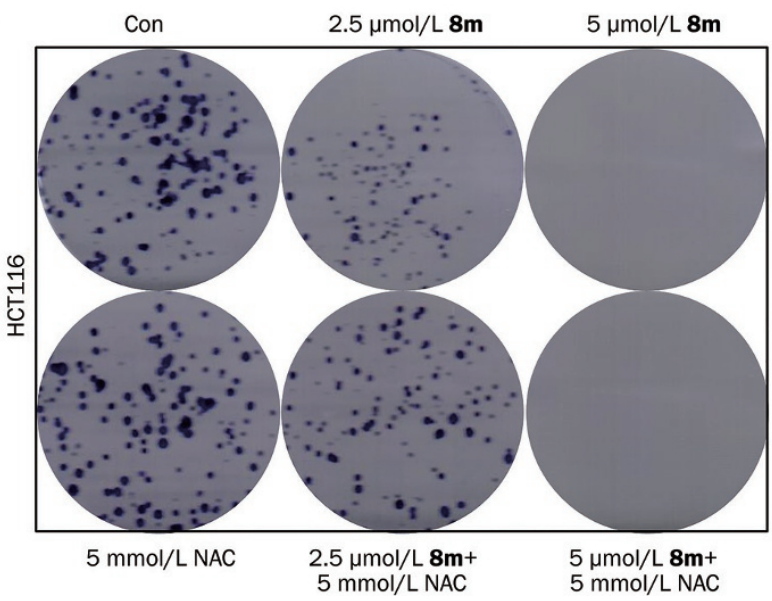

$7.5 \mu \mathrm{mol} / \mathrm{L} 8 \mathrm{~m} 24 \mathrm{~h}$
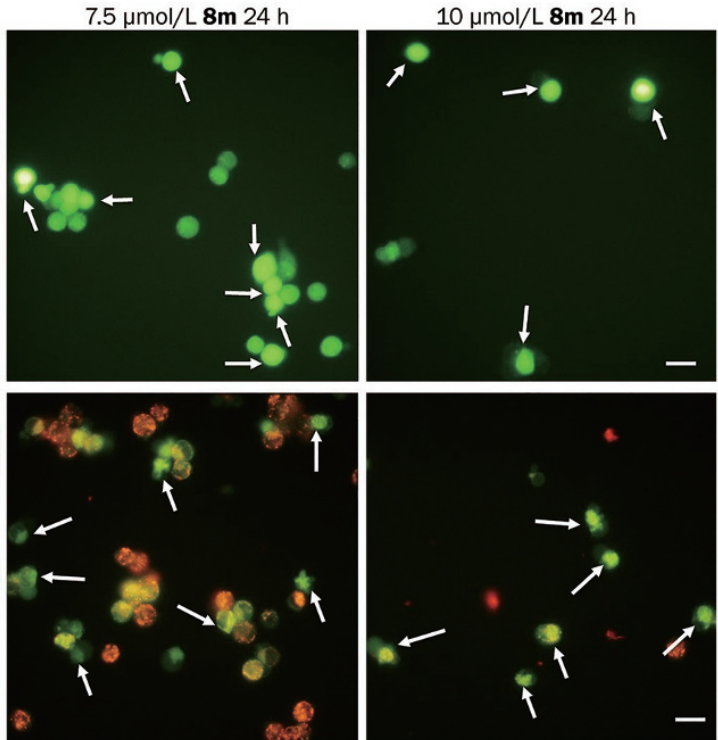

F

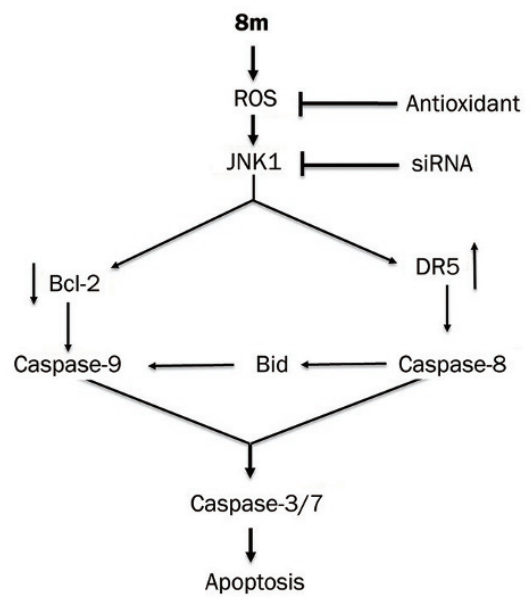

Figure 5. ROS mediation of $\mathbf{8 m}$-induced cell death. HCT116 cells were treated with the indicated concentrations of $\mathbf{8 m}$ for $24 \mathrm{~h}$. (A) ROS was detected using a fluorescent microscope and the H2-DCFDA fluorescent probe. The arrows point to cells producing ROS. Scale bar, $20 \mu \mathrm{m}$. (B) Mitochondrial transmembrane potential dissipation was measured using the JC-1 stain. Depolarization of mitochondrial transmembrane potential is specifically indicated by a decrease in the red-to-green fluorescence intensity ratio. Scale bar, $20 \mu \mathrm{m}$. (C) After a 12-h incubation in standard culture conditions, HCT116 cells were pretreated with GSH $(0,1,10$, or $20 \mathrm{mmol} / \mathrm{L})$ for $1 \mathrm{~h}$ and then treated with $5 \mu \mathrm{mol} / \mathrm{L} \mathbf{8 m}$ for $12 \mathrm{~h}$. Whole-cell extracts were prepared and analyzed by Western blotting using the specified antibodies. (D) After a 12-h incubation under standard culture conditions, HCT116 cells were pretreated with $\operatorname{NAC}(0,1,10$, or $20 \mathrm{mmol} / \mathrm{L})$ for $1 \mathrm{~h}$ and then were treated with $5 \mu \mathrm{mol} / \mathrm{L} \mathbf{8 m}$ for $12 \mathrm{~h}$. Whole-cell extracts were prepared and analyzed by Western blotting using the specified antibodies. (E) Cells were treated with $0,2.5$, or $5 \mu \mathrm{mol} / \mathrm{L} 8 \mathrm{~m}$ and/or co-treated with $5 \mathrm{mmol} / \mathrm{L} \mathrm{NAC}$ for the colony formation assay. Culture medium was changed every 3 to $4 \mathrm{~d}$, and colony formation was inactivated after $14 \mathrm{~d}$. (F) Schematic representation of signaling pathways through which $\mathbf{8 m}$ induces the apoptosis of HCT116 cells. 
cell lines SW480 and HCT116 with $\mathrm{IC}_{50}$ values of 6.77 and 3.33 $\mu \mathrm{mol} / \mathrm{L}$, respectively. HCT116 cells were selected for further study to determine the distinct mechanisms of $\mathbf{8 m}$-induced cytotoxicity. DAPI staining of $8 \mathrm{~m}$-treated HCT116 cells demonstrated the presence of condensed chromatin and apoptotic bodies. Profound increases in externalized phosphatidylserine, a hallmark of early apoptosis, was also detected via flow cytometric analysis of $\mathbf{8 m}$-treated cancer cells. These results suggested that $8 \mathrm{~m}$ decreased cell viability by inducing the apoptosis of HCT116 cells.

To examine the mechanisms underlying $8 \mathrm{~m}$-induced apoptosis, we analyzed the changes in apoptotic proteins after $8 \mathrm{~m}$ treatment. An apparent induction of cleaved caspase- 8 and caspase- 9 was detected, indicating that $8 \mathrm{~m}$-induced apoptosis involved both the intrinsic mitochondrial-initiated pathway and the extrinsic death receptor-mediated pathway. This result suggests that HCT116 cells are type II cells capable of amplifying apoptotic signaling initiated by the extrinsic pathway through the recruitment of the intrinsic pathway ${ }^{[40]}$, whereby activated caspase-9 (cleaved caspase-9) subsequently cleaves caspase- 7 and caspase- 3 to effect downstream apoptotic events ${ }^{[5]}$. PARP, a family of proteins involved in DNA repair in response to environmental stress, can be cleaved by the caspase- 3 executioner protein. Cleavage of PARP facilitates cellular disassembly and serves as a marker of cells undergoing apoptosis ${ }^{[11]}$. In the current study, we found that $8 \mathrm{~m}$ treatment increased the cleavage of caspase-7, caspase-3, and PARP in a concentration- and time-dependent manner. Bcl-2 provides a distinct survival signal to cancer cells to support neoplastic growth; therefore, we conducted an intense mechanistic study to assess the ability of Bcl-2 to suppress $8 \mathrm{~m}$-induced apoptosis ${ }^{[42]}$. 8m-induced down-regulation of $\mathrm{Bcl}-2$ can cause the release of cytochrome $c$ from the mitochondria to the cytoplasm, thereby initiating the intrinsic apoptotic signaling pathway ${ }^{[35]}$. However, it is not known whether the initiation of the intrinsic pathway is more greatly influenced by Bcl-2 down-regulation or by crosstalk with the extrinsic pathway. Further studies are warranted to elucidate the mechanism underlying the activation of the intrinsic pathway. Given its ability to trigger specific apoptotic cancer cell death without targeting normal cells, TRAIL is a promising target for cancer therapy. Nevertheless, resistance to TRAIL, resulting from decreased levels of DR4 and DR5 and/or mutations in these proteins, has been a treatment issue ${ }^{[43]}$. Furthermore, accumulating evidence indicates that the down-regulation or mutation of death receptors (DRs) may allow malignant cells to avoid destruction by the immune system ${ }^{[44]}$. Therefore, agents that increase the levels of DRs in cancer cells may prevent certain types of drug resistance and should therefore be investigated. In our study, $8 \mathrm{~m}$ induced the expression of DR5 in a concentration- and time-dependent manner. This result is even more noteworthy because real-time PCR analysis suggested that after $8 \mathrm{~m}$ treatment, DR5 may play a more important role than DR4 in apoptosis and that DR5 can transmit apoptotic signals to caspase- 8 to initiate the extrinsic apoptotic pathway ${ }^{[6]}$. This evidence demonstrated the potential of $8 \mathrm{~m}$ as an antitumor small molecule that can up-regulate the expression of DR5, thereby promoting cancer cell apoptosis and decreasing drug resistance.

A large body of evidence has shown that certain anticancer agents trigger apoptosis through the modulation of MAPK $^{[14,21,32]}$, which can play an important role in the mediation of DR5 ${ }^{[9,13]}$. In this work, $8 \mathrm{~m}$ treatment induced $\mathrm{p} 38$ and JNK phosphorylation, whereas JNK1 inhibition (but not inhibition of JNK2 or p38) abrogated $8 \mathrm{~m}$-induced JNK phosphorylation as well as the cleavage of caspases and PARP. However, the function of $\mathbf{8 m}$-induced p38 phosphorylation remains unclear. Figures $3 \mathrm{~A}, 3 \mathrm{~B}, 4 \mathrm{~B}, 5 \mathrm{C}$, and $5 \mathrm{D}$ show the JNK proteins, which have distinct molecular masses of $46 \mathrm{kDa}$ (p46 JNK, the lower lane) and $54 \mathrm{kDa}$ (p54 JNK, the upper lane) and are largely, but not exclusively, composed of the JNK1 and JNK2 isoforms, respectively ${ }^{[23]}$. Integrating the results from the siRNA knockdown experiments, we have confirmed that $8 \mathrm{~m}$-induced JNK phosphorylation largely (but not absolutely) results from the production of phosphor-JNK1. The JNK1 signaling pathway tends to have a specific role in mediating apoptosis in several types of cancer cells, whereas JNK2 is involved particularly in cell survival signaling ${ }^{[23,24]}$. The activation of JNK1 can lead to the phosphorylation of Bcl2 , resulting in Bcl-2 degradation and an inhibition of its antiapoptotic properties ${ }^{[45,46]}$. However, $8 \mathrm{~m}$-induced JNK1 phosphorylation was only barely detectable after transfection with JNK1 siRNA. Knocking down JNK1, but not JNK2, rescued the $8 \mathrm{~m}$-induced down-regulation of DR5, Bcl-2, and other apoptotic proteins. Apoptosis studies via flow cytometry also demonstrated a pro-apoptotic role for JNK1 in our system. However, inhibiting JNK1 completely abolish 8m-induced cell death, as shown by Western blotting and flow cytometric assays. Thus, it is likely that JNK1-independent mechanisms also participate in $8 \mathrm{~m}$-induced apoptosis.

Environmental stimuli, especially drug stress, are known to damage mitochondrial dynamics and affect mitochondrial function, and vice versa. Mitochondrial dysfunctions include ROS overproduction and mitochondrial membrane depolarization, both of which can induce apoptosis ${ }^{[47]}$. In this study, using the fluorescent stains H2-DCFDA and JC-1, we detected $8 \mathrm{~m}$-induced ROS production and mitochondrial membrane depolarization in an $8 \mathrm{~m}$-concentration-dependent manner. ROS, as an upstream regulator of JNK, plays an important role in various cellular responses, such as proliferation, differentiation, necrosis, and especially cell apoptosis ${ }^{[13,20]}$. To examine the effect of ROS on JNK and other pathways, two potent antioxidants, NAC and GSH, were employed to detect the changes resulting from $8 \mathrm{~m}$-induced pathway activation or inhibition in antioxidant-pretreated cells. We observed that pretreatment with NAC or GSH prevented both $\mathbf{8 m}$-induced JNK phosphorylation and caspase cleavage. The colony formation assay revealed that HCT116 cells co-cultured with NAC generated much larger colonies than the $8 \mathrm{~m}$-alone control. This indicated that ROS signaling was involved in the $8 \mathrm{~m}$-induced apoptosis of HCT116 cells and the phosphorylation of JNK1. Combined with the conclusion that JNK1 played a pro-apoptotic role in 
our system, we can conclude that $\mathbf{8 m}$-induced apoptosis is ROS-JNK1 dependent (Figure 5F). In accordance with our results, many anticancer drugs induce the apoptosis of cancer cells via this pathway. For example, selenite-induced apoptosis in Chang liver cells involved ROS-JNK1 signaling ${ }^{[48]}$, and an ROS-JNK1-mediated process affected shikonin-induced apoptosis in Bcr/Abl-positive chronic myelogenous leukemia (CML) cells ${ }^{[49]}$.

In conclusion, our study demonstrated that a new benzimidazole acridine derivative $(\mathbf{8 m})$ had cytotoxic activity in human colon cancer cell lines. Both the intrinsic and extrinsic death pathways were activated by $\mathbf{8 m}$ in a concentration- and timedependent manner. Further investigation into its mechanism of action confirmed that the ROS-JNK1 pathway played an important role in mediating $\mathbf{8 m}$-induced apoptosis. Furthermore, we demonstrated that $\mathbf{8 m}$ can upregulate DR5, a hallmark of effective anticancer agents. Therefore, our findings provide a basis for future investigations aimed at elucidating the role of apoptosis in colon cancer therapy.

\section{Acknowledgements}

This work was supported by grants from the National Natural Science Foundation of China (21272134 and 21402105) and the Shenzhen Municipal government SZSITIC (ZDSY20120619141412872, JCYJ20130402164027386, KC2013ZDZJ0019A and CXB201104210013A).

\section{Author contribution}

Kang CHEN performed the research and drafted the manuscript; Bi-zhu CHU designed the research; Lu-lu LI and Bin LI performed some experiments; Chun-mei GAO provided the 8m compound; and Qin-sheng SUN, Zhi-fa SHEN, Feng LIU, and Yu-yang JIANG provided supervision and support in the project.

\section{References}

1 Gupta GP, Massague J. Cancer metastasis: building a framework. Cell 2006; 127: 679-95.

2 Allen WL, Coyle VM, Jithesh PV, Proutski I, Stevenson L, Fenning C, et al. Clinical determinants of response to irinotecan-based therapy derived from cell line models. Clin Cancer Res 2008; 14: 6647-55.

3 Hare Jl, Neijzen RW, Anantha M, Dos Santos N, Harasym N, Webb MS, et al. Treatment of colorectal cancer using a combination of liposomal irinotecan (Irinophore C) and 5-fluorouracil. PLoS One 2013; 8: e62349.

4 Galligan L, Longley DB, McEwan M, Wilson TR, McLaughlin K, Johnston PG. Chemotherapy and TRAIL-mediated colon cancer cell death: the roles of p53, TRAIL receptors, and c-FLIP. Mol Cancer Ther 2005; 4: 2026-36.

5 Taylor RC, Cullen SP, Martin SJ. Apoptosis: controlled demolition at the cellular level. Nat Rev Mol Cell Biol 2008; 9: 231-41.

6 Ashkenazi A. Death receptors: signaling and modulation. Science 1998; 281: 1305-8.

7 Fulda S, Debatin KM. Extrinsic versus intrinsic apoptosis pathways in anticancer chemotherapy. Oncogene 2006; 25: 4798-811.

8 Wang G, Wang X, Yu H, Wei S, Williams N, Holmes DL, et al. Smallmolecule activation of the TRAIL receptor DR5 in human cancer cells. Nat Chem Biol 2013; 9: 84-9.
9 Dolloff NG, Mayes PA, Hart LS, Dicker DT, Humphreys R, El-Deiry WS. Off-target lapatinib activity sensitizes colon cancer cells through TRAIL death receptor up-regulation. Sci Transl Med 2011; 3: 86ra50.

10 Mattarollo SR, Kenna T, Nieda M, Nicol AJ. Chemotherapy pretreatment sensitizes solid tumor-derived cell lines to $V$ alpha $24+$ NKT cellmediated cytotoxicity. Int J Cancer 2006; 119: 1630-7.

11 Suliman A, Lam A, Datta R, Srivastava RK. Intracellular mechanisms of TRAIL: apoptosis through mitochondrial-dependent and -independent pathways. Oncogene 2001; 20: 2122-33.

12 He PX, Zhang J, Che YS, He QJ, Chen Y, Ding J. G226, a new epipolythiodioxopiperazine derivative, triggers DNA damage and apoptosis in human cancer cells in vitro via ROS generation. Acta Pharmacol Sin 2014; 35: 1546-55.

13 Trivedi R, Maurya R, Mishra DP. Medicarpin, a legume phytoalexin sensitizes myeloid leukemia cells to TRAlL-induced apoptosis through the induction of DR5 and activation of the ROS-JNK-CHOP pathway. Cell Death Dis 2014; 5: e1465.

14 Yang CB, Pei WJ, Zhao J, Cheng YY, Zheng XH, Rong JH. Bornyl caffeate induces apoptosis in human breast cancer MCF-7 cells via the ROSand JNK-mediated pathways. Acta Pharmacol Sin 2014; 35: 113-23.

15 Koçer M, Nazıroğlu M, Koçer G, Sönmez TT. Effects of bisphosphonate on oxidative stress levels in patients with different types of cancer. Cancer Invest 2013; 32: 37-42.

16 Kockar MC, Naziroglu M, Celik O, Tola HT, Bayram D, Koyu A. $\mathrm{N}$-acetylcysteine modulates doxorubicin-induced oxidative stress and antioxidant vitamin concentrations in liver of rats. Cell Biochem Funct 2010; 28: 673-7.

17 Kocer M, Naziroglu M. Effects of 5-fluorouracil on oxidative stress and calcium levels in the blood of patients with newly diagnosed colorectal cancer. Biol Trace Elem Res 2013; 155: 327-32.

18 Naziroglu M, Cig B, Ozgul C. Neuroprotection induced by $\mathrm{N}$-acetylcysteine against cytosolic glutathione depletion-induced $\mathrm{Ca}^{2+}$ influx in dorsal root ganglion neurons of mice: role of TRPV1 channels. Neuroscience 2013; 242: 151-60.

19 Ribas V, Garcia-Ruiz C, Fernandez-Checa JC. Glutathione and mitochondria. Front Pharmacol 2014; 5: 151.

$20 \mathrm{Wu}$ WS. The signaling mechanism of ROS in tumor progression. Cancer Metastasis Rev 2006; 25: 695-705.

21 Raman M, Chen W, Cobb MH. Differential regulation and properties of MAPKs. Oncogene 2007; 26: 3100-12.

22 Davis RJ. Signal transduction by the JNK group of MAP kinases. Cell 2000; 103: 239-52.

23 Liu J, Minemoto Y, Lin A. c-Jun N-terminal protein kinase 1 (JNK1), but not JNK2, is essential for tumor necrosis factor alpha-induced c-Jun kinase activation and apoptosis. Mol Cell Biol 2004; 24: 10844-56.

24 Sabapathy K, Hochedlinger K, Nam SY, Bauer A, Karin M, Wagner EF. Distinct roles for JNK1 and JNK2 in regulating JNK activity and c-Jundependent cell proliferation. Mol Cell 2004; 15: 713-25.

25 Rao PS, Ray UK, Gupta PB, Rao DV, Islam A, Rajput P, et al. Identification, isolation and characterization of new impurity in rabeprazole sodium. J Pharm Biomed Anal 2010; 52: 620-4.

26 Gaba M, Singh S, Mohan C. Benzimidazole: An emerging scaffold for analgesic and anti-inflammatory agents. Eur J Med Chem 2014; 76: 494-505.

27 He Y, Yang J, Wu B, Risen L, Swayze EE. Synthesis and biological evaluations of novel benzimidazoles as potential antibacterial agents. Bioorg Med Chem Lett 2004; 14: 1217-20.

28 Li Y, Tan C, Gao C, Zhang C, Luan X, Chen X, et al. Discovery of benzimidazole derivatives as novel multi-target EGFR, VEGFR-2, and PDGFR kinase inhibitors. Bioorg Med Chem 2011; 19: 4529-35.

29 Ketron AC, Denny WA, Graves DE, Osheroff N. Amsacrine as a topoiso- 
merase II poison: importance of drug-DNA interactions. Biochemistry 2012; 51: 1730-9.

30 Vispe S, Vandenberghe I, Robin M, Annereau JP, Creancier L, Pique $\mathrm{V}$, et al. Novel tetra-acridine derivatives as dual inhibitors of topoisomerase II and the human proteasome. Biochem Pharmacol 2007; 73: $1863-72$.

31 Baguley BC, Wakelin LPG, Jacintho JD, Kovacic P. Mechanisms of action of DNA intercalating acridine-based drugs: how important are contributions from electron transfer and oxidative stress? Curr Med Chem 2003; 10: 2643-49.

32 Chang WL, Chang CS, Chiang PC, Ho YF, Liu JF, Chang KW, et al. 2-Phenyl-5-(pyrrolidin-1-yl)-1-(3,4,5-trimethoxybenzyl)-1H-benzimidazole, a benzimidazole derivative, inhibits growth of human prostate cancer cells by affecting tubulin and c-Jun $\mathrm{N}$-terminal kinase. $\mathrm{Br} \mathrm{J}$ Pharmacol 2010; 160: 1677-89.

33 Li L, Cao W, Zheng W, Fan C, Chen T. Ruthenium complexes containing 2,6-bis(benzimidazolyl)pyridine derivatives induce cancer cell apoptosis by triggering DNA damage-mediated p53 phosphorylation. Dalton Trans 2012; 41: 12766-72.

34 Gao C, Li B, Zhang B, Sun Q, Li L, Li X, et al. Synthesis and biological evaluation of benzimidazole acridine derivatives as potential DNAbinding and apoptosis-inducing agents. Bioorg Med Chem 2015; 23 : 1800-7.

35 Kluck RM. The release of cytochrome $c$ from mitochondria: a primary site for Bcl-2 regulation of apoptosis. Science 1997; 275: 1132-36.

36 Li L, Zheng BB, Ma LS, Sun X, Chang JJ, Xie WD, et al. Telekin suppresses human hepatocellular carcinoma cells in vitro by inducing $\mathrm{G}_{2} / \mathrm{M}$ phase arrest via the p38 MAPK signaling pathway. Acta Pharmacol Sin 2014; 35: 1311-22.

37 Ohtsuka T, Zhou T. Bisindolylmaleimide VIII enhances DR5-mediated apoptosis through the MKK4/JNK/p38 kinase and the mitochondrial pathways. J Biol Chem 2002; 277: 29294-303.

38 Ou YW, Zhao ZT, Wu CY, Xu BN, Song YM, Zhan QM. Mig-2 attenuates cisplatin-induced apoptosis of human glioma cells in vitro through AKT/JNK and AKT/p38 signaling pathways. Acta Pharmacol Sin 2014; 35: 1199-206.
39 Hsin YH, Chen CF, Huang S, Shih TS, Lai PS, Chueh PJ. The apoptotic effect of nanosilver is mediated by a ROS- and JNK-dependent mechanism involving the mitochondrial pathway in NIH3T3 cells. Toxicol Lett 2008; 179: 130-9.

40 Ozoren N, El-Deiry WS. Defining characteristics of Types I and II apoptotic cells in response to TRAIL. Neoplasia 2002; 4: 551-7.

41 Agarwal A, Mahfouz RZ, Sharma RK, Sarkar O, Mangrola D, Mathur PP. Potential biological role of poly (ADP-ribose) polymerase (PARP) in male gametes. Reprod Biol Endocrinol 2009; 7: 143.

42 Lee JW, Cho MK. Phenethyl isothiocyanate induced apoptosis via down regulation of $\mathrm{Bcl}-2 / \mathrm{XIAP}$ and triggering of the mitochondrial pathway in MCF-7 cells. Arch Pharm Res 2008; 31: 1604-12.

43 Johnstone RW, Frew AJ, Smyth MJ. The TRAIL apoptotic pathway in cancer onset, progression and therapy. Nat Rev Cancer 2008; 8: 782-98.

44 Igney FH KP. Immune escape of tumors: apoptosis resistance and tumor counterattack. J Leukoc Biol 2002; 71: 907-20.

45 Lin SS, Bassik MC, Suh H, Nishino M, Arroyo JD, Hahn WC, et al. PP2A regulates BCL-2 phosphorylation and proteasome-mediated degradation at the endoplasmic reticulum. J Biol Chem 2006; 281: 23003-12.

46 Yanamadala V, Negoro H, Gunaratnam L, Kong T, Denker BM. Galpha12 stimulates apoptosis in epithelial cells through JNK1mediated Bcl-2 degradation and up-regulation of IkappaBalpha. J Biol Chem 2007; 282: 24352-63.

47 Yi L, Zongyuan Y, Cheng G, Lingyun Z, Guilian Y, Wei G. Quercetin enhances apoptotic effect of tumor necrosis factor-related apoptosisinducing ligand (TRAIL) in ovarian cancer cells through reactive oxygen species (ROS) mediated CCAAT enhancer-binding protein homologous protein (CHOP)-death receptor 5 pathway. Cancer Science 2014; 105 : 520-7.

48 Yong-sook Kim D-yJ. Involvement of ROS and JNK1 in selenite-induced apoptosis in chang liver cells. J Biol Chem 2004; 36: 157-64.

49 Mao X, Yu CR, Li WH, Li WX. Induction of apoptosis by shikonin through a ROS/JNK-mediated process in Bcr/Abl-positive chronic myelogenous leukemia (CML) cells. Cell Res 2008; 18: 879-88. 